\title{
Exploring prospects of novel drugs for tuberculosis
}

This article was published in the following Dove Press journal:

Drug Design, Development and Therapy

6 September 2012

Number of times this article has been viewed

\author{
Saskia Janssen ${ }^{1,2}$ \\ Rajesh Jayachandran ${ }^{3}$ \\ Lulama Khathi ${ }^{4}$ \\ Jakob Zinsstag ${ }^{5}$ \\ Martin P Grobusch 1,2,6 \\ Jean Pieters ${ }^{3}$ \\ 'Center for Tropical Medicine and \\ Travel Medicine, Department of \\ Infectious Diseases, Division of \\ Internal Medicine, Academic Medical \\ Center, University of Amsterdam, \\ The Netherlands; ${ }^{2}$ Institute of \\ Tropical Medicine, University of \\ Tübingen, Germany; ${ }^{3}$ Biozentrum, \\ University of Basel, Basel, Switzerland; \\ ${ }^{4}$ National Reference Laboratory \\ for Tuberculosis, National Health \\ Laboratory Services, Johannesburg, \\ South Africa; ${ }^{5}$ Swiss Tropical and \\ Public Health Institute, Associated \\ Institute to the University of Basel, \\ Basel, Switzerland; 'Department \\ of Infectious Diseases, Division \\ of Internal Medicine, Faculty of \\ Health Sciences, University of the \\ Witwatersrand, Johannesburg, \\ South Africa
}

Correspondence: Jean Pieters Biozentrum, Klingelbergstrasse 50, CH 4056 Basel, Switzerland

$\mathrm{Tel}+416 \quad$ I267 I494

Fax +4I6 I267 2I I48

Email jean.pieters@unibas.ch
Abstract: Tuberculosis remains a disease with an enormous impact on public health worldwide. With the continuously increasing epidemic of drug-resistant tuberculosis, new drugs are desperately needed. However, even for the treatment of drug-sensitive tuberculosis, new drugs are required to shorten the treatment duration and thereby prevent development of drug resistance. Within the past ten years, major advances in tuberculosis drug research have been made, leading to a considerable number of antimycobacterial compounds which are now in the pipeline. Here we discuss a number of these novel promising tuberculosis drugs, as well as the discovery of two new potential drug targets for the development of novel effective drugs to curb the tuberculosis pandemic, ie, the coronin 1 and protein kinase $G$ pathways. Protein kinase $G$ is secreted by mycobacteria and is responsible for blocking lysosomal delivery within the macrophage. Coronin 1 is responsible for activating the phosphatase, calcineurin, and thereby preventing phagosome-lysosome fusion within the macrophage. Blocking these two pathways may lead to rapid killing of mycobacteria.

Keywords: tuberculosis, treatment, drug-resistance, drug targets

\section{Introduction}

Mycobacterium tuberculosis continues to be one of the world's most debilitating and deadly pathogens. Tuberculosis accounted for an estimated 1.7 million deaths in 2009 , and the incidence is higher than ever before, with 9.4 million new cases. ${ }^{1}$ Efficacious drugs exist, but their success in treatment depends on rigid implementation of therapy, access to treatment, and adherence over a considerable time span. This has consequences regarding the logistics of tuberculosis control programs, which currently fail in many settings in the view of the human immunodeficiency virus (HIV)/acquired immune deficiency syndrome copandemic. There are still sizeable populations, especially in sub-Saharan Africa, which have no access to tuberculosis control through the Directly Observed Treatment Short course (DOTS) strategy of the World Health Organization. In addition to the urgent need for novel drugs, DOTS coverage should be increased further to reduce ongoing transmission. ${ }^{2}$

Although tuberculosis drug research over the past 10 years has led to the development of a few novel agents which are currently in different stages of clinical evaluation, the preceding 30 years had been painfully silent in the field of tuberculosis drug research. The rise in drug resistance among $M$. tuberculosis strains has become a severe threat to public health on a global scale. With an estimated 440,000 cases of multidrug-resistant tuberculosis (defined as Mycobacterium tuberculosis resistance to at least rifampicin and isoniazid) and extensively drug-resistant tuberculosis (defined as multidrug-resistant 
tuberculosis plus resistance to a fluoroquinolone and at least one second-line injectable agent, ie, amikacin, kanamycin, and/or capreomycin) now being reported in 58 different countries, the epidemic is ever increasing. ${ }^{3}$

Although mortality rates for extensively drug-resistant tuberculosis have now been reduced from the initially reported nearly $100 \%{ }^{4}$ to approximately $45 \%,{ }^{5}$ it remains a challenge to treat infected individuals because of the long treatment duration required and inevitable usage of substances of high cost and with unfavorable safety profiles. In HIV-positive patients in Southern Africa, at least 50\% of all adults have been documented as suffering from tuberculosis. ${ }^{6}$ When looking at coinfections in confirmed tuberculosis cases with HIV, these reached up to $95 \%$ in the Johannesburg setting, which is the highest coinfection rate ever described to date in the literature. ${ }^{7}$ All this puts additional pressure on the need to develop more effective strategies to curb the tuberculosis pandemic, and in particular, this includes novel, more effective, and well tolerated drugs.

Apart from the need for new drugs to treat drug-resistant tuberculosis, several challenges are faced, even for drugsusceptible tuberculosis. Drug-susceptible tuberculosis still needs to be treated with a regimen containing at least four different drugs, and treatment should be continued for at least 6 months. Compliance and adherence would increase with shorter treatment courses containing fewer drugs. Furthermore, there are important interactions with the rifamycins and the most widely used antiretroviral drugs for HIV, making coinfection with tuberculosis and HIV complicated to treat and creating a need for new drugs which lack these interactions. Short and safe treatment regimens for latent tuberculosis (with an estimated 2 billion people living with latent tuberculosis serving as a continuous reservoir for new active cases) still need to be developed.

In this review, we briefly outline the problem of multidrug-resistant and extensively drug-resistant tuberculosis, give an overview of novel regimens currently in clinical evaluation, describe the mechanisms of survival of M. tuberculosis in infected hosts, and propose avenues currently being addressed in the authors' laboratories that may contribute towards the development of therapies targeting drug-susceptible, multidrug-resistant, and extensively drugresistant tuberculosis.

\section{Multidrug and extensively drug-resistant tuberculosis}

Control programs are often overburdened in highly endemic countries, giving rise to $M$. tuberculosis drug resistance due to a range of predisposing factors and circumstances. ${ }^{8}$ The emergence of multidrug-resistant and extensively drugresistant tuberculosis strains has been prominent in parts of the former USSR, particularly the Baltic republics and some Western megametropolitan areas such as New York City, as well as India, China, and the African continent, with a focus on its south, as highlighted by the first described outbreak of an extensively drug-resistant strain of $M$. tuberculosis in KwaZulu Natal, with excessive mortality. ${ }^{4}$

The mechanisms involved in the development of multidrug resistant and extensively drug-resistant tuberculosis are complex and determined by the mycobacterium, the host, and iatrogenic factors. Firstly, mycobacteria have a high degree of intrinsic resistance to most antibiotics and chemotherapeutics due to the low permeability of the mycobacterial cell wall. ${ }^{9}$ Numerous chromosomal mutations have been associated with the development of drug resistance in tuberculosis. ${ }^{10}$ One of several host factors predisposing to tuberculosis drug resistance is immunosuppression. ${ }^{11}$ However, development of drug resistance against tuberculosis is mainly associated with intensive drug use and lack of compliance with treatment. Epidemics of drug-resistant tuberculosis, as for example in South Africa, can be largely attributed to poor performance of control programs and low cure rates over many years. ${ }^{12}$

\section{Novel drugs to combat TB}

The drugs currently used for tuberculosis were discovered before 1970. After that, the world of tuberculosis drug research remained silent for over 30 years. Over the past decade, drug development efforts have increased, fuelled by the upcoming threat of drug resistance and the tuberculosis epidemics which are ever increasing, and also influenced by the expansion of the HIV pandemic.

At the time of writing, there are currently at least 13 drugs in different stages of preclinical or clinical evaluation (http:// www.newtbdrugs.org/pipeline.php) for the treatment of tuberculosis (see Table 1). ${ }^{5,13-26}$ They can be roughly divided into three categories, ie, novel drugs, drugs currently licensed for other indications but "repurposed" for tuberculosis, and the current first-line tuberculosis drugs which are reevaluated to optimize their efficacy. There are two main lines of development, ie, improving treatment of drug-sensitive tuberculosis (cutting down on the required duration of therapy) to yield higher cure rates and curb development of resistance, and improving and shortening treatment of drugresistant tuberculosis. In the authors' view, these should not be considered as competing but as complementary areas of 
Table I Overview of antituberculous drugs currently in different stages of clinical development, the chemical class to which they belong, and their mechanism of action

\begin{tabular}{|c|c|c|c|}
\hline Drug & Chemical class & Mechanism of action & $\begin{array}{l}\text { Phase of clinical } \\
\text { development }\end{array}$ \\
\hline \multicolumn{4}{|l|}{ Novel drugs } \\
\hline Bedaquiline (TMC207) ${ }^{18,19,22}$ & Diaryquinolones & PPI blocking mycobacterial ATP synthase & II, III \\
\hline \multicolumn{4}{|l|}{ (Tibotec BVBA, Beerse, Belgium) } \\
\hline SQI0923 & Ethylenediamine & Inhibition of cell wall synthesis & II \\
\hline \multicolumn{4}{|l|}{ (Sequella, NIH, Rockville, MD) } \\
\hline Delamanid (OPC-67683) $)^{13,21,25}$ & Nitroimidazoles & Inhibition of cell wall mycolic acid biosynthesis & III \\
\hline \multicolumn{4}{|c|}{ (Otsuka Pharmaceuticals Inc, Tokyo, Japan) } \\
\hline PA- $824^{20}$ & Nitroimidazoles & Inhibition of cell wall mycolic acid biosynthesis & II \\
\hline \multicolumn{4}{|l|}{ (TB Alliance, New York, NY) } \\
\hline \multicolumn{4}{|c|}{ Licensed drugs being repurposed for use in tuberculosis } \\
\hline Moxifloxacin $5,24,26$ & Fluoroquinolones & Inhibition of DNA replication and transcription & III \\
\hline Gatifloxacin 24,26 & Fluoroquinolones & Inhibition of DNA replication and transcription & III \\
\hline Linezolid ${ }^{15,16}$ & Oxalidinones & Inhibition of protein synthesis & II \\
\hline \multicolumn{4}{|c|}{ Tuberculosis drugs re-evaluated to optimize efficacy } \\
\hline Rifapentin ${ }^{14,17}$ & Rifamycins & Inhibition of DNA-dependent RNA synthesis & II, III \\
\hline
\end{tabular}

Note: References mentioned are clinical trials reporting on efficacy, safety, and pharmacokinetics.

interest because both need to be addressed in order to turn the tide against tuberculosis at the "drug front".

Although compared with ten years ago many promising new drugs are being developed, a further understanding of the pathogenesis of tuberculosis, latent infection, and development of drug resistance is needed in order to identify novel drug targets which may pave the way for further drug development.

\section{Mechanisms of survival of M. tuberculosis within infected hosts}

To be able to interfere with the persistence mechanisms developed by M. tuberculosis, it is important to understand the virulence mechanisms that the organism utilizes to establish itself within its human host. After entry into the host organism via the respiratory tract, mycobacteria are phagocytosed by macrophages and resist lysosomal degradation, thus allowing them to survive as well as to multiply within macrophage phagosomes, thereby circumventing the normal host response that would normally result in lysosomal degradation of the bacilli. ${ }^{27-29}$ Subsequently, M. tuberculosis uses an array of strategies to remain viable within an infected host, including escape into the cytosol, ${ }^{30}$ residence outside macrophages, for example, within caseous regions of granulomas, ${ }^{31,32}$ modulation of nitric and oxygen stress ${ }^{33}$ and regulation of autophagic processes. ${ }^{34}$ In fact, M. tuberculosis, as one of the most successful pathogens known, has evolved an array of mechanisms to counteract the host immune response at virtually every imaginable level. ${ }^{35}$
A comprehensive discussion of these mechanisms falls well beyond the scope of this paper, and the reader is referred to recent excellent review articles. Here, we focus on those mechanisms that M. tuberculosis has evolved to modulate intraphagosomal survival, and given the attenuation of M. tuberculosis strains that have lost the capacity to survive within macrophages, ${ }^{36,37}$ or even reside within the macrophage cytosol, ${ }^{30}$ targeting intramacrophage survival mechanisms is likely to contribute to the control of M. tuberculosis proliferation.

Escape of mycobacteria from host defenses may also allow reactivation of tuberculosis in adults. This occurs when so-called dormant foci left in the host after a primary infection become reactivated. ${ }^{38}$ Reactivation can occur when the host immune system fails to control bacterial growth or when the immune system is deteriorating, eg, as a result of malnutrition, overcrowding, or stress, ${ }^{39}$ resulting in uncontrolled bacterial growth and death of the host.

Because of the important role of the macrophage phagosome as an escape site for M. tuberculosis, substantial efforts have been directed at defining the biology of mycobacterial entry and survival inside phagosomes. The mycobacterial phagosome, because it is derived from the plasma membrane, has many features in common with the membrane..$^{40-43}$ However, in contrast with normal phagocytosis, in which phagosomal content is delivered to lysosomes either by maturation or through vesicular traffic of intermediate vesicles, mycobacteria actively resist lysosomal delivery. ${ }^{27}$

Several strategies have been used to define mycobacterial virulence factors. These have included characterization of the erp gene product through generation of mutant strains, ${ }^{44}$ 
proteins with a regulatory function, such as sigma factors as well as enzymes that function in different mycobacterial biochemical pathways, such as isocitrate lyase and glutamine synthetase. ${ }^{45-48}$ On the host side, the recently identified interferon-gamma-induced $L R G-47$ gene was suggested to act as a vacuolar trafficking regulator necessary for the control of intracellular mycobacterial growth. ${ }^{49}$

Different signaling pathways have been implicated in the survival mechanisms for pathogenic mycobacteria, including modulation of $\mathrm{Ca}^{2+}$ signaling upon entry ${ }^{50}$ and regulation of phagosome-lysosome fusion through phosphorylation/ dephosphorylation. ${ }^{51}$

Thus, M. tuberculosis uses multiple strategies to circumvent innate host immunity to infections. This unique capacity of $M$. tuberculosis to remain viable within the mycobacterial phagosome by avoiding lysosomal delivery within macrophages may be important for its capacity not only to survive for prolonged periods but also to cause severe disease and death in infected individuals.

\section{Discovery of novel drug targets to block survival of M. tuberculosis}

The capacity of $M$. tuberculosis to cause disease lies in its ability to avoid destruction within those cells that normally destroy all incoming bacteria, namely the macrophages. While bacteria are normally internalized into phagosomes from which they are transported to lysosomes where they are destroyed, M. tuberculosis actively blocks their transfer to lysosomes, allowing them to survive for prolonged times within phagosomes. A long-term interest in the mechanisms utilized by $M$. tuberculosis to circumvent host resistance, thereby allowing these bacteria to proliferate and cause disease, has been maintained in the laboratories of RJ and JP.

Recent work has unraveled two pathways via which M. tuberculosis manages to survive within host cells. One mechanism relies on the secretion of a eukaryotic-like kinase by $M$. tuberculosis, ie, protein kinase $\mathrm{G}$, the expression of which is essential to block lysosomal delivery. ${ }^{52,53}$ A second strategy relies on the retention of a host molecule, coronin 1, at the mycobacterial phagosome that is responsible for activating the phosphatase, calcineurin. ${ }^{54,55}$ Interestingly, current work suggests that targeting of protein kinase $G$ as well as the coronin $1 /$ calcineurin pathway may result in rapid killing of internalized mycobacteria. Whether or not inhibition of these recently discovered pathways would block survival and proliferation of multidrug-resistant and extensively drug-resistant strains of $M$. tuberculosis remains to be analyzed.

\section{Targeting protein kinase $\mathbf{G}$ to promote killing of $M$. tuberculosis}

Protein kinase $\mathrm{G}$ was discovered in a search for mycobacterial factors that promote survival of pathogenic mycobacteria within host macrophages. Protein kinase $G$ is a eukaryotic-like serine/threonine protein kinase that is not required for mycobacterial growth per se but is essential for its survival within host macrophages (Figure 1), and has been discussed in detail elsewhere. ${ }^{53,56}$ Protein kinase $\mathrm{G}$ is one of the 11 serine/threonine protein kinases found in

\section{Nonpathogenic mycobacteria}

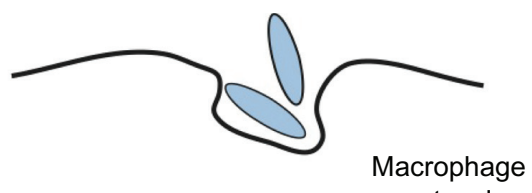

cytosol

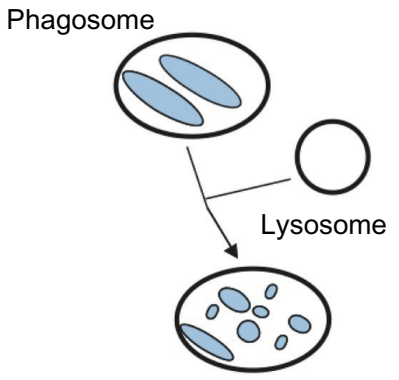

Degradation

\section{Pathogenic mycobacteria}
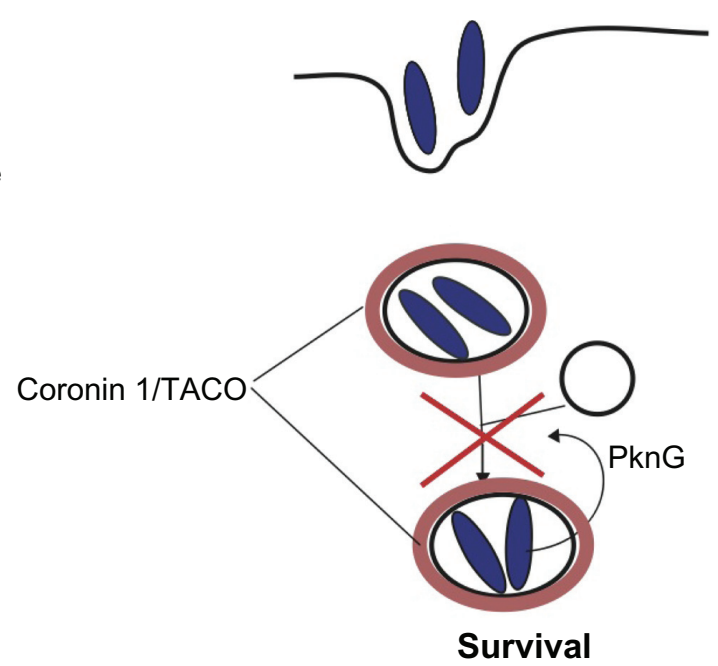

Figure I Protein kinase G-mediated and coronin I-mediated survival within host macrophages.

(c) Copyright National Academy of Sciences, USA. Reproduced with permission from Scherr N, Honnappa S, Kunz G, et al. Structural basis for the specific inhibition of protein kinase G, a virulence factor of Mycobacterium tuberculosis. Proc Natl Acad Sci U S A. 2007; 104:1 2151-12156. ${ }^{52}$ 
M. tuberculosis, and the only soluble kinase maintained in the genome of $M$. leprae that is believed to have retained the minimal set of genes essential for virulence. ${ }^{57}$ The presence of domains typically found in proteins from eukaryotic species as well as the finding that protein kinase $\mathrm{G}$ is dispensable for in vitro growth of $M$. tuberculosis ${ }^{56,58}$ suggests that protein kinase $\mathrm{G}$ has arrived in the M. tuberculosis genome through horizontal gene transfer and has been maintained as a virulence factor important for its survival inside the eukaryotic host. ${ }^{59}$

Importantly, mycobacteria overexpressing a kinase-dead mutant of protein kinase $\mathrm{G}$ are rapidly transferred to lysosomes and killed, thus demonstrating that protein kinase $\mathrm{G}$ activity is crucial for mycobacterial survival. The fact that protein kinase $\mathrm{G}$ is translocated into the host cytosol suggests that compounds aimed at blocking protein kinase $\mathrm{G}$ activity do not require translocation across the only slightly permeable mycobacterial cell wall..$^{53}$

Together, these findings make protein kinase $\mathrm{G}$ an attractive and promising drug candidate. Indeed, blocking protein kinase $\mathrm{G}$ activity by a specific small molecular weight inhibitor, ie, the tetrahydrobenzothiophene, AX20017, results in rapid transfer of mycobacteria to lysosomes and killing of intracellularly residing bacilli. ${ }^{53,56}$ Furthermore, detailed biochemical analysis of the domains of protein kinase $G$ has revealed several key residues that are crucial for both its in vitro kinase activity as well as the virulence function of protein kinase $\mathrm{G}$ within infected macrophages. ${ }^{60,61}$

Two recently obtained sets of results have contributed to the validation of protein kinase $\mathrm{G}$ as a potential drug target. First, infecting mice with $M$. tuberculosis lacking protein kinase $G$ resulted in dramatically prolonged survival of infected mice (mean survival time prolonged from 12 weeks to $>50$ weeks, unpublished data). This suggests that targeting protein kinase $\mathrm{G}$ in vivo may significantly alter the outcome of infection with M. tuberculosis. Second, we have recently obtained the x-ray structure of protein kinase G complexed with its inhibitor (Figure 2). The structure shows that protein kinase $\mathrm{G}$ contains a unique ATP-binding pocket that is different from any of the 491 human kinases known; in fact, a potent protein kinase $\mathrm{G}$ inhibitor showed virtually no activity when tested against a panel of 28 different kinases originating from the six major kinase groups. Thus, the structure of protein kinase $\mathrm{G}$ was revealed to be distinct from the host cell kinases, allowing its efficient targeting without blocking host cell kinases. ${ }^{52}$ Interestingly, docking studies using the tridimensional structure of protein kinase $\mathrm{G}$ identified potential novel inhibitors of the withanolide compound class. ${ }^{62}$

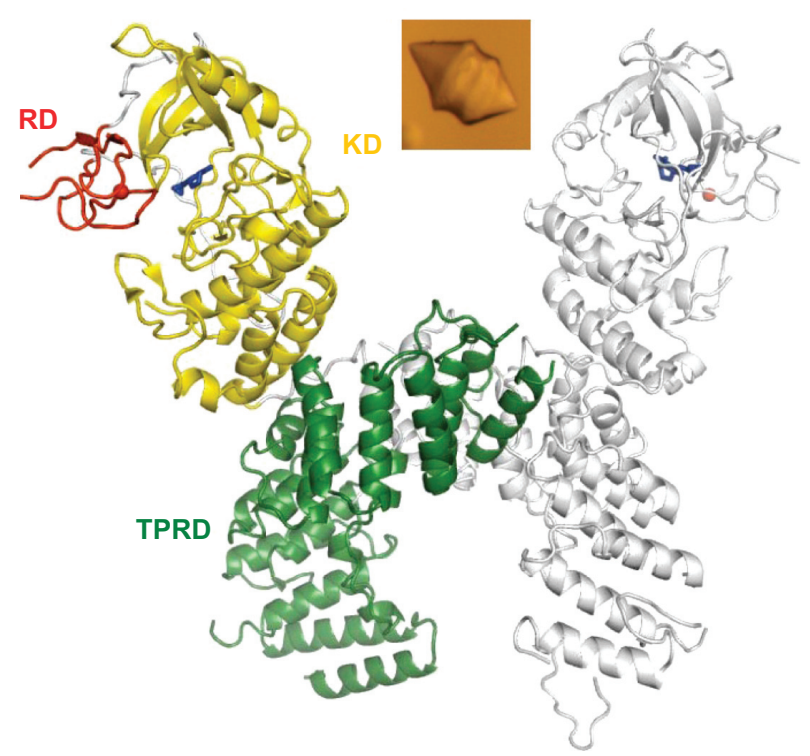

Figure 2 Structure of protein kinase $\mathrm{G}$ with inhibitor.

Note: Inset: protein kinase G crystal.

(C) Copyright National Academy of Sciences, USA. Reproduced with permission from Scherr N, Honnappa S, Kunz G, et al. Structural basis for the specific inhibition of protein kinase G, a virulence factor of Mycobacterium tuberculosis. Proc Natl Acad Sci U S A. 2007; 104:12151-12156. ${ }^{52}$

These preliminary findings suggest that targeting protein kinase G may enable inhibition of $M$. tuberculosis growth within host cells by allowing the macrophages to carry out their natural innate immune function, namely, shuttling M. tuberculosis to degradative lysosomes.

\section{Inhibition of coronin I-mediated signaling to block resistant M. tuberculosis}

In 1999, coronin 1, also known as tryptophan aspartate-containing coat protein or $\mathrm{p} 57,{ }^{63}$ was described as a protein that was actively retained in mycobacterial phagosomes, and was predicted to be involved in blocking the delivery of pathogenic mycobacteria to lysosomes (Figure 1) ${ }^{54}$ This suggested an essential role for coronin 1 in protecting the mycobacterial phagosome from fusion with lysosomes, ${ }^{54,64}$ confirmed subsequently using siRNA-mediated knockdown of coronin $1 .{ }^{65-67}$ Moreover, mycobacteria are effectively destroyed within Kupffer cells, the major macrophages in the liver that do not express coronin $1 .{ }^{54}$

How coronin 1 mediates the survival of pathogenic mycobacteria has been revealed recently by generating mice lacking coronin 1. It turns out that while mice lacking coronin 1 are perfectly healthy, coronin 1 is required for activation of the $\mathrm{Ca}^{2+}$-dependent phosphatase, calcineurin. ${ }^{55}$ In wild-type macrophages, upon internalization of mycobacteria, this phosphatase becomes activated, thereby blocking 
phagosome-lysosome fusion by an as yet unknown mechanism and allowing survival of mycobacteria. In the absence of coronin 1, calcineurin activation does not occur, resulting in phagosome-lysosome fusion and intracellular killing of the internalized mycobacteria. Strikingly, genetic depletion of coronin 1 can be phenocopied by addition of the calcineurin inhibitors, cyclosporin A and FK506 (Figure 3). Thus, it appears that coronin 1 has evolved to activate $\mathrm{Ca}^{2+}$-dependent signaling reactions in macrophages, thereby promoting the survival of pathogenic mycobacteria. ${ }^{55}$

These results suggest that blocking the coronin 1 signaling pathway may allow intracellular killing of $M$. tuberculosis. Preliminary results indeed suggest that in vivo administration of calcineurin inhibitors allows rerouting of $M$. tuberculosis inside macrophages. ${ }^{55}$ Because this newly discovered pathway is unlikely to be related to any of the mechanisms that are currently targeted by available tuberculosis drugs, we anticipate that blockers of the coronin 1 pathway may be useful for treatment of drug-resistant tuberculosis.

\section{Therapeutic potential of agents blocking protein kinase $\mathbf{G}$ and coronin I}

Preliminary data have shown that blocking either the protein kinase $\mathrm{G}$ or the coronin 1 pathway may be highly specific for inhibiting growth of $M$. tuberculosis inside macrophages without affecting host functioning. For protein kinase $\mathrm{G}$ inhibition, a potent inhibitor of protein kinase $G^{53}$ was not active against a panel of 28 human kinases that were selected to represent the entire human kinome. ${ }^{52}$ In addition, when macrophages were exposed to high concentrations of these inhibitors, all measurable cellular functions appeared normal.

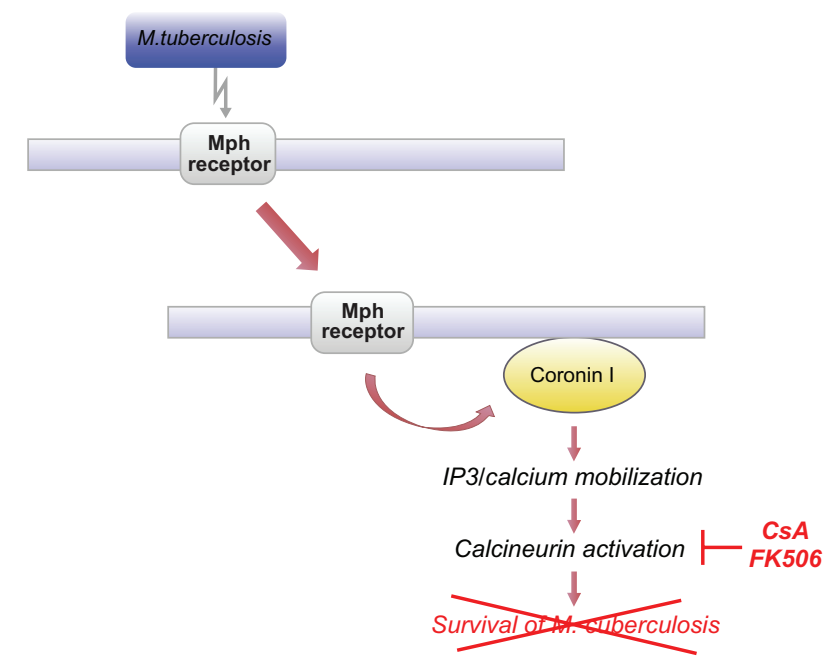

Figure 3 Mechanism of action of coronin I in intracellular survival of pathogenic mycobacteria.
With regard to coronin 1 inhibition, the clearest indication that coronin 1 can be blocked without obvious adverse effects is the phenotype of coronin 1-deficient mice. These mice develop normally, are healthy, and show no obvious phenotype. ${ }^{55}$ In addition, the inhibitory protocol that we have developed to block the coronin 1-signaling pathway is based on use of cyclosporin A and/or FK506, both of which are drugs approved for use in humans. ${ }^{68,69}$

\section{Conclusion}

It is reassuring that after many years, a tuberculosis drug pipeline is now developing. Moreover, several novel pathways essential for $M$. tuberculosis survival are currently being explored, including the protein kinase $\mathrm{G}$ and coronin 1 pathways, which have potential to serve as novel drug targets for treatment of both drug-sensitive and drug-resistant tuberculosis. Whilst pressing on with the development of drugs and optimized combination and usage of existing drugs at the "outcome" end of the pipeline, concerted effort is needed to expand further the portfolio of novel drug targets and to identify novel leads.

\section{Acknowledgments}

JP, JZ, and MPG received funding from the UBS Optimus Foundation, Basel, Switzerland, for drug target identification in drug-resistant tuberculosis. RJ is a recipient of the Cloetta Medical Research Fellowship program. Work in the laboratory of JP is further supported by the Swiss National Science Foundation and the Kanton Basel-Stadt. Patents related to this work have been filed (WO2007110385A2 and WO2009112542A1) by the University of Basel.

\section{Disclosure}

The authors report no conflicts of interest in this work.

\section{References}

1. World Health Organization. Global tuberculosis control report. 2010.

2. Zinsstag J, Taleb MO, Craig PS. Health of nomadic pastoralists: new approaches towards equity effectiveness. Trop Med Int Health. 2006;11:565-568.

3. World Health Organization. M/XDR TB. Multi-drug and extensively drug-resistant tuberculosis - 2010 global report on surveillance and response. Available from: http://www.who.int/tb/features_archive/m_ xdrtb_facts/en/index.html. Accessed July 12, 2012.

4. Gandhi NR, Moll A, Sturm AW, et al. Extensively drug-resistant tuberculosis as a cause of death in patients co-infected with tuberculosis and HIV in a rural area of South Africa. Lancet. 2006;368:1575-1580.

5. Dheda K, Shean K, Zumla A, et al. Early treatment outcomes and HIV status of patients with extensively drug-resistant tuberculosis in South Africa: a retrospective cohort study. Lancet. 2010;375:1798-1807.

6. Nunn P, Reid A, De Cock KM. Tuberculosis and HIV infection: the global setting. J Infect Dis. 2007;196 Suppl 1:S5-S14. 
7. John MA, Menezes CN, Chita G, Sanne I, Grobusch MP. High tuberculosis and HIV coinfection rate, Johannesburg. Emerg Infect Dis. 2007;13:795-796.

8. Grobusch MP. Drug-resistant and extensively drug-resistant tuberculosis in southern Africa. Curr Opin Pulm Med. 2010;16:180-185.

9. Jarlier V, Nikaido H. Mycobacterial cell wall: structure and role in natural resistance to antibiotics. FEMS Microbiol Lett. 1994;123:11-18.

10. Sandgren A, Strong M, Muthukrishnan P, Weiner BK, Church GM, Murray MB. Tuberculosis drug resistance mutation database. PLoS Med. 2009;6:e2.

11. Jiang JR, Yen SY, Wang JY. Increased prevalence of primary drugresistant pulmonary tuberculosis in immunocompromised patients. Respirology. 2011;16:308-313.

12. Abdool Karim SS, Churchyard GJ, Abdool KQ, Lawn SD. HIV infection and tuberculosis in South Africa: an urgent need to escalate the public health response. Lancet. 2009;374:921-933.

13. Gler MT, Skripconoka V, Sanchez-Garavito E, et al. Delamanid for multidrug-resistant pulmonary tuberculosis. $N$ Engl J Med. 2012;366:2151-2160.

14. Bock NN, Sterling TR, Hamilton CD, et al. A prospective, randomized, double-blind study of the tolerability of rifapentine 600, 900, and $1,200 \mathrm{mg}$ plus isoniazid in the continuation phase of tuberculosis treatment. Am J Respir Crit Care Med. 2002;165:1526-1530.

15. Migliori GB, Eker B, Richardson MD, et al. A retrospective TBNET assessment of linezolid safety, tolerability and efficacy in multidrugresistant tuberculosis. Eur Respir J. 2009;34:387-393.

16. Schecter GF, Scott C, True L, Raftery A, Flood J, Mase S. Linezolid in the treatment of multidrug-resistant tuberculosis. Clin Infect Dis. 2010;50:49-55.

17. Sterling TR, Villarino ME, Borisov AS, et al. Three months of rifapentine and isoniazid for latent tuberculosis infection. $N$ Engl J Med. 2011;365:2155-2166.

18. Andries K, Verhasselt P, Guillemont J, et al. A diarylquinoline drug active on the ATP synthase of Mycobacterium tuberculosis. Science. 2005;307:223-227.

19. Diacon AH, Pym A, Grobusch M, et al. The diarylquinoline TMC207 for multidrug-resistant tuberculosis. $N$ Engl J Med. 2009;360:2397-2405.

20. Diacon AH, Dawson R, Hanekom M, et al. Early bactericidal activity and pharmacokinetics of PA-824 in smear-positive tuberculosis patients. Antimicrob Agents Chemother. 2010;54:3402-3407.

21. Diacon AH, Dawson R, Hanekom M, et al. Early bactericidal activity of delamanid (OPC-67683) in smear-positive pulmonary tuberculosis patients. Int J Tuberc Lung Dis. 2011;15:949-954.

22. Diacon AH, Donald PR, Pym A, et al. Randomized pilot trial of 8 weeks of bedaquiline (TMC207) for MDR-TB: long-term outcome, tolerability and effect on emergence of drug resistance. Antimicrob Agents Chemother. 2012;56:3271-3276.

23. Jia L, Tomaszewski JE, Hanrahan C, et al. Pharmacodynamics and pharmacokinetics of SQ109, a new diamine-based antitubercular drug. Br J Pharmacol. 2005;144:80-87.

24. Johnson JL, Hadad DJ, Boom WH, et al. Early and extended early bactericidal activity of levofloxacin, gatifloxacin and moxifloxacin in pulmonary tuberculosis. Int J Tuberc Lung Dis. 2006;10:605-612.

25. Matsumoto M, Hashizume H, Tomishige T, et al. OPC-67683, a nitrodihydro-imidazooxazole derivative with promising action against tuberculosis in vitro and in mice. PLoS Med. 2006;3:e466.

26. Rustomjee R, Lienhardt C, Kanyok T, et al. A Phase II study of the sterilising activities of ofloxacin, gatifloxacin and moxifloxacin in pulmonary tuberculosis. Int J Tuberc Lung Dis. 2008;12:128-138.

27. Armstrong JA, Hart PD. Response of cultured macrophages to Mycobacterium tuberculosis, with observations on fusion of lysosomes with phagosomes. J Exp Med. 1971;134:713-740.

28. Pieters J. Entry and survival of pathogenic mycobacteria in macrophages. Microbes Infect. 2001;3:249-255.

29. Russell DG. Mycobacterium tuberculosis: here today, and here tomorrow. Nat Rev Mol Cell Biol. 2001;2:569-577.
30. van der Wel N, Hava D, Houben D, et al. M. tuberculosis and M. leprae translocate from the phagolysosome to the cytosol in myeloid cells. Cell. 2007;129:1287-1298.

31. Gengenbacher M, Kaufmann SH. Mycobacterium tuberculosis: success through dormancy. FEMS Microbiol Rev. 2012;36:514-532.

32. Reece ST, Kaufmann SH. Floating between the poles of pathology and protection: can we pin down the granuloma in tuberculosis? Curr Opin Microbiol. 2012;15:63-70.

33. Nathan C. Role of iNOS in human host defense. Science. 2006;312: 1874-1875.

34. Gutierrez MG, Master SS, Singh SB, Taylor GA, Colombo MI, Deretic V. Autophagy is a defense mechanism inhibiting BCG and Mycobacterium tuberculosis survival in infected macrophages. Cell. 2004;119:753-766.

35. Huynh KK, Joshi SA, Brown EJ. A delicate dance: host response to mycobacteria. Curr Opin Immunol. 2011;23:464-472.

36. Berthet FX, Lagranderie M, Gounon P, et al. Attenuation of virulence by disruption of the Mycobacterium tuberculosis erp gene. Science. 1998;282:759-762.

37. McKinney JD, Honer Zu BK, Munoz-Elias EJ, et al. Persistence of Mycobacterium tuberculosis in macrophages and mice requires the glyoxylate shunt enzyme isocitrate lyase. Nature. 2000;406:735-738.

38. Barry CE III. New horizons in the treatment of tuberculosis. Biochem Pharmacol. 1997;54:1165-1172.

39. Chan J, Tian Y, Tanaka KE, et al. Effects of protein calorie malnutrition on tuberculosis in mice. Proc Natl Acad Sci US A. 1996;93:14857-14861.

40. Brown EJ. Complement receptors and phagocytosis. Curr Opin Immunol. $1991 ; 3: 76-82$

41. Hasan Z, Schlax C, Kuhn L, et al. Isolation and characterization of the mycobacterial phagosome: segregation from the endosomal/lysosomal pathway. Mol Microbiol. 1997;24:545-553.

42. Russell DG, Dant J, Sturgill-Koszycki S. Mycobacterium avium- and Mycobacterium tuberculosis-containing vacuoles are dynamic, fusioncompetent vesicles that are accessible to glycosphingolipids from the host cell plasmalemma. J Immunol. 1996;156:4764-4773.

43. Schlesinger LS. Entry of Mycobacterium tuberculosis into mononuclear phagocytes. Curr Top Microbiol Immunol. 1996;215:71-96.

44. Berthet FX, Lagranderie M, Gounon P, et al. Attenuation of virulence by disruption of the Mycobacterium tuberculosis erp gene. Science. 1998;282:759-762.

45. Glickman MS, Cox JS, Jacobs WR Jr. A novel mycolic acid cyclopropane synthetase is required for cording, persistence, and virulence of Mycobacterium tuberculosis. Mol Cell. 2000;5:717-727.

46. Harth G, Horwitz MA. Inhibition of Mycobacterium tuberculosis glutamine synthetase as a novel antibiotic strategy against tuberculosis: demonstration of efficacy in vivo. Infect Immun. 2003;71:456-464.

47. Hingley-Wilson SM, Sambandamurthy VK, Jacobs WR Jr. Survival perspectives from the world's most successful pathogen, Mycobacterium tuberculosis. Nat Immunol. 2003;4:949-955.

48. Honer Zu BK, Miczak A, Swenson DL, Russell DG. Characterization of activity and expression of isocitrate lyase in Mycobacterium avium and Mycobacterium tuberculosis. J Bacteriol. 1999;181:7161-7167.

49. MacMicking JD, Taylor GA, McKinney JD. Immune control of tuberculosis by IFN-gamma-inducible LRG-47. Science. 2003;302:654-659.

50. Malik ZA, Thompson CR, Hashimi S, Porter B, Iyer SS, Kusner DJ. Cutting edge: Mycobacterium tuberculosis blocks Ca2+ signaling and phagosome maturation in human macrophages via specific inhibition of sphingosine kinase. J Immunol. 2003;170:2811-2815.

51. Vergne I, Chua J, Lee HH, Lucas M, Belisle J, Deretic V. Mechanism of phagolysosome biogenesis block by viable Mycobacterium tuberculosis. Proc Natl Acad Sci U S A. 2005;102:4033-4038.

52. Scherr N, Honnappa S, Kunz G, et al. Structural basis for the specific inhibition of protein kinase $\mathrm{G}$, a virulence factor of Mycobacterium tuberculosis. Proc Natl Acad Sci U S A. 2007;104:12151-12156.

53. Walburger A, Koul A, Ferrari G, et al. Protein kinase G from pathogenic mycobacteria promotes survival within macrophages. Science. 2004;304:1800-1804. 
54. Ferrari G, Langen H, Naito M, Pieters J. A coat protein on phagosomes involved in the intracellular survival of mycobacteria. Cell. 1999;97:435-447.

55. Jayachandran R, Sundaramurthy V, Combaluzier B, et al. Survival of mycobacteria in macrophages is mediated by coronin 1-dependent activation of calcineurin. Cell. 2007;130:37-50.

56. Nguyen L, Walburger A, Houben E, et al. Role of protein kinase G in growth and glutamine metabolism of Mycobacterium bovis BCG. J Bacteriol. 2005;187:5852-5856.

57. Cole ST, Eiglmeier K, Parkhill J, et al. Massive gene decay in the leprosy bacillus. Nature. 2001;409:1007-1011.

58. Av-Gay Y, Everett M. The eukaryotic-like Ser/Thr protein kinases of Mycobacterium tuberculosis. Trends Microbiol. 2000;8: $238-244$.

59. Leonard CJ, Aravind L, Koonin EV. Novel families of putative protein kinases in bacteria and archaea: evolution of the "eukaryotic" protein kinase superfamily. Genome Res. 1998;8:1038-1047.

60. Scherr N, Muller P, Perisa D, Combaluzier B, Jeno P, Pieters J. Survival of pathogenic mycobacteria in macrophages is mediated through autophosphorylation of protein kinase G. J Bacteriol. 2009; 191:4546-4554.

61. Tiwari D, Singh RK, Goswami K, Verma SK, Prakash B, Nandicoori VK. Key residues in Mycobacterium tuberculosis protein kinase $\mathrm{G}$ play a role in regulating kinase activity and survival in the host. J Biol Chem. 2009;284:27467-27479.
62. Santhi N, Aishwarya S. Insights from the molecular docking of withanolide derivatives to the target protein $\mathrm{PknG}$ from Mycobacterium tuberculosis. Bioinformation. 2011;7:1-4.

63. Suzuki K, Nishihata J, Arai Y, et al. Molecular cloning of a novel actinbinding protein, $\mathrm{p} 57$, with a WD repeat and a leucine zipper motif. FEBS Lett. 1995;364:283-288.

64. Tailleux L, Neyrolles O, Honore-Bouakline S, et al. Constrained intracellular survival of Mycobacterium tuberculosis in human dendritic cells. J Immunol. 2003;170:1939-1948.

65. Jayachandran R, Gatfield J, Massner J, Albrecht I, Zanolari B, Pieters J. RNA interference in $\mathrm{J} 774$ macrophages reveals a role for coronin 1 in mycobacterial trafficking but not in actin-dependent processes. $\mathrm{Mol}$ Biol Cell. 2008;19:1241-1251.

66. Kumar D, Nath L, Kamal MA, et al. Genome-wide analysis of the host intracellular network that regulates survival of Mycobacterium tuberculosis. Cell. 2010;140:731-743.

67. Seto S, Tsujimura K, Koide Y. Coronin-1a inhibits autophagosome formation around Mycobacterium tuberculosis-containing phagosomes and assists mycobacterial survival in macrophages. Cell Microbiol. 2012;14:710-727.

68. Jain A, Khanna A, Molmenti EP, Rishi N, Fung JJ. Immunosuppressive therapy. Surg Clin North Am. 1999;79:59-76.

69. Rovira P, Mascarell L, Truffa-Bachi P. The impact of immunosuppressive drugs on the analysis of T cell activation. Curr Med Chem. 2000;7: 673-692.
Drug Design, Development and Therapy

\section{Publish your work in this journal}

Drug Design, Development and Therapy is an international, peerreviewed open-access journal that spans the spectrum of drug design and development through to clinical applications. Clinical outcomes, patient safety, and programs for the development and effective, safe, and sustained use of medicines are a feature of the journal, which

\section{Dovepress}

has also been accepted for indexing on PubMed Central. The manuscript management system is completely online and includes a very quick and fair peer-review system, which is all easy to use. Visit http://www.dovepress.com/testimonials.php to read real quotes from published authors.

Submit your manuscript here: http://www.dovepress.com/drug-design-development-and-therapy-journal 